\title{
Synthesis of SBA-15 using natural clay from low-grade potash ores of a salt lake in Qinghai, China
}

\author{
Feng Zhang ${ }^{\mathrm{a}}$, Chunyan Sun ${ }^{\mathrm{b}}$, Shengfang $\mathrm{Li}^{\mathrm{c}}$, Lin Yang ${ }^{\mathrm{d}}$ and Xianyu Chao ${ }^{\mathrm{e}}$ \\ College of Chemical Engineering, Qinghai University, Xining, 810016, China \\ azfxs8022@163.com, bsunchunyan@qhu.edu.cn, 'c1620449624@qq.com,d905233826@qq.com, \\ e249122812@qq.com
}

Keywords: mesoporous material, natural clay, hydrothermal synthesis, SBA-15.

\begin{abstract}
Hexagonally ordered mesoporous silica SBA-15 was successfully synthesized for the first time using natural clay from low-grade potash ores of a salt lake in Qinghai, China, without addition of silica reagents. The influence of changes in processing parameters, such as activation method, hydrothermal conditions, and calcinations temperature, on the textural characteristics of the SBA-15 products was studied. A pretreatment process involving iron-removing and alkali fusion was critical to the successful use of natural clay from low-grade potash ores as a source of silica in the surfactant-templated hydrothermal synthesis of SBA-15. The product was characterized by X-ray fluorescence (XRF), X-ray diffraction (XRD), Fourier-transform infrared spectroscopy (FT-IR), N2 adsorption/ desorption isotherms, transmission electron microscopy (TEM) and TG-DSC analysis. The resulting mesophase had a surface area of $546.6 \mathrm{~m} 2 . \mathrm{g}-1$ and an average pore diameter of $6.2 \mathrm{~nm}$ with narrow pore size distribution. The results indicated that salt lake clay was a promising low-cost precursor for the production of mesoporous molecular sieve.
\end{abstract}

\section{Introduction}

Much attention has been paid to mesoporous materials which are considered as potential application in the fields of catalyst [1-3], adsorbents [4-6], separation and host-guest chemistry [7-9], etc. Among them, the hexagonally ordered mesoporous molecular sieve SBA-15 has been widely investigated in the past decade because of its simple preparation, high hydrothermal stability, large surface area and tunable nanoscale pores [10]. The common mesoporous materials are usually synthesized using expensive and toxic organosilicate as silica source, such as tetramethylorthosilicate (TMOS) or tetraethylorthosilicate (TEOS), with the help of cooperative surfactant templating. To alleviate the environmental and economic problems, attempts have been made to develop nontoxic substitute precursors. In particular, the possibility of preparing mesoporous materials from low-cost natural aluminosilicate clay minerals has been explored because of similarities between the abundance and structural units of the latter and those of mesoporous materials. Although many reports have been focused on the preparation of mesoporous silicas M41S from attapulgite [11], halloysite [12], saponite [13], and volclay [14], to the best of our knowledge, there is no report about the preparation of SBA-15 from nature clay minerals.

Extensive clay accumulation occurs in low-grade sylvinite ores, such as those mined from salt lakes in Qaidam Basin of Qinghai, northwestern China. Most of the potash ores containing only small amounts of insoluble clays have been depleted over the last few years, and only large reserves of clay-containing ores typically bearing 30\%-60\% insoluble materials remained. Clay accumulation is a consistent concern in the potash industry and a problem that is not only limited to Qinghai potash ores. Approaches through which the clay from low-grade potash ore may be utilized have become a major consideration in potassium recovery processes.

In this paper, the natural clay which were collected directly from a salt lake in Qaidam Basin, Qinghai, was utilized as a raw material to prepare highly pure hexagonally ordered mesoporous silica, SBA-15, using hydrothermal method and the optimum conditions were obtained based on the process parameters. 


\section{Experimental Sections}

\subsection{Materials}

A raw representative sample of clay was collected from the potash ore deposit of a salt lake in Qaidam Basin, and denoted QHS. The raw QHS was crushed in a crusher. The crushed sample was thoroughly washed with distilled water to remove water-soluble components, such as $\mathrm{K}$ and $\mathrm{Na}$, and then dried overnight at $60^{\circ} \mathrm{C}$.

All chemicals were purchased from Aladdin Industrial Corporation and used as received without further purification.

\subsection{Pretreatment of QHS}

Iron-Removing: The dried clay $(10 \mathrm{~g})$ and $\mathrm{HCl}(7.6 \mathrm{M}, 150 \mathrm{~mL})$ were mixed, and stirred in $80^{\circ} \mathrm{C}$ water bath for $4 \mathrm{~h}$ to remove excess iron. The mixture was filtered, washed to neutrality with distilled water and dried at $80{ }^{\circ} \mathrm{C}$ over night.

Two different activating treatment of clay as follows were investigated for comparison.

Fusion of QHS by $\mathrm{NaOH}$ : $\mathrm{NaOH}$ and iron-removed QHS at a 1.5:1 weight ratio were mixed well and fused in an MgO ceramic crucible at $500{ }^{\circ} \mathrm{C}$ for $4 \mathrm{~h}$. The fused mixture was cooled to room temperature to obtain a pale and loose powder that was then used as a direct silica source to prepare mesoporous silicate.

Thermally activation by calcination: The raw QHS(10g) and iron-removed QHS(10g) were placed in two $\mathrm{MgO}$ ceramic crucibles respectively and calcined at $800^{\circ} \mathrm{C}$ for $4 \mathrm{~h}$. Then the samples after calcining were cooled to room temperature to obtain loose powder.

\subsection{Synthesis of SBA-15}

The optimal synthesis conditions were as follows: alkali fused QHS powder ( $3.0 \mathrm{~g}$ ) was added to distilled water ( $30 \mathrm{~mL}$ ) with vigorous stirring for $100 \mathrm{~min}$ in a water bath at $80{ }^{\circ} \mathrm{C}$ to obtain a cloudy aqueous solution. The resultant suspension was filtered to separate the solid from the liquid phase. The clear supernatant was used as $\mathrm{Si}$ source. The solution of surfactant templating $\mathrm{EO}_{20} \mathrm{PO}_{70} \mathrm{EO}_{20}$ (P123) (1.0g) dissolved in $\mathrm{HCl}(2 \mathrm{M}, 30 \mathrm{~mL})$ was stirred in water bath at $40{ }^{\circ} \mathrm{C}$, above clear supernatant was added dropwisely and stirred for $24 \mathrm{~h}$ in $40{ }^{\circ} \mathrm{C}$ water bath. The white gel was observed. Then white gel was transferred to $80 \mathrm{~mL}$ Teflon-lined hydrothermal autoclave, and crystallized at $80{ }^{\circ} \mathrm{C}$ for $24 \mathrm{~h}$ under static conditions. After crystallization, the solid product was separated by filtration and washed thoroughly several times with deionized water until the filtrate $\mathrm{pH}$ was less than 9 . The solid product dried overnight at $80{ }^{\circ} \mathrm{C}$, and heated to $540{ }^{\circ} \mathrm{C}$ with rate of $2{ }^{\circ} \mathrm{C}$ $/ \mathrm{min}$ and calcined for $6 \mathrm{~h}$ to remove the template P123.

\subsection{Characterization}

The chemical compositions of the samples were determined by X-ray fluorescence (XRF) analysis on a Rigaku ZSX Primus II X-ray fluorescence spectrometer. Solid sample pellets were used for the present experiment. The spectrometer was equipped with a $\mathrm{Rh} \mathrm{X}$-ray tube and run at $60 \mathrm{kV}$ voltage and $150 \mathrm{~mA}$ current.

Wide-angle X-ray diffraction (WAXRD) patterns over the $2 \theta$ range of $5^{\circ}-60^{\circ}$ were obtained using a Rigaku D-MAX2500X diffractometer with $\mathrm{Cu} \mathrm{K \alpha}(40 \mathrm{kV}$ and $200 \mathrm{~mA})$. The scanning speed was $4^{\circ} / \mathrm{min}$, and the step size was $0.02^{\circ}$. Small-angle X-ray diffraction (SAXRD) analysis was carried out using a PANnalytical X'Pert PRO diffractometer over the $2 \theta$ range of $0.6^{\circ}-10^{\circ}$. Cu Ka $(40 \mathrm{kV}$ and 20 $\mathrm{mA}$ ) radiation was used. Here, the step size was $0.0080^{\circ}$, and the nominal collection time was $50.16 \mathrm{~s}$ per step.

Transmission electron microscopy (TEM) images were taken using a Tecnai TF20 G2 FEG-TEM at $200 \mathrm{kV}$ accelerating voltage with a standard single-tilt holder. The sample was dispersed into anhydrous alcohol with ultrasonic treatment for $10 \mathrm{~min}$, and the solution was deposited on a Cu grid.

Fourier-transform infrared (FT-IR) spectra were obtained with a Perkin-Elmer FT-IR Spectrum BX-II spectrometer by using 16 scans with $4 \mathrm{~cm}^{-1}$ resolution. For analysis, $0.5 \mathrm{mg}$ of the sample was pressed with $400 \mathrm{mg}$ of $\mathrm{KBr}$ into a pellet, and spectra were recorded over the range of $400-4000 \mathrm{~cm}^{-1}$ at room temperature. For background correction, the spectrum against air was measured and subtracted from the results. 
Nitrogen gas adsorption-desorption isotherms were obtained at $-196{ }^{\circ} \mathrm{C}$ using an ASAP $2020 \mathrm{M}$ specific surface area and pore size analyzer. Prior to the adsorption experiment, the materials were vacuum-dried at $200{ }^{\circ} \mathrm{C}$ for $10 \mathrm{~h}$. The specific surface area and pore size distribution of the product were calculated by the BET and BJH methods, respectively, using the nitrogen adsorption branch of the isotherms obtained.

TG-DSC analysis of sample was performed on a NETZSCH-STA499F3 instrument in an alumina pan at a $10^{\circ} \mathrm{C} / \mathrm{min}$ heating rate from $40^{\circ} \mathrm{C}$ to $1100{ }^{\circ} \mathrm{C}$ under a $\mathrm{N}_{2}$ flow.

\section{Results and discussion}

\subsection{Effects on SBA-15 preparation}

The natural clay collected from the potash ore deposit of a salt lake in Qaidam Basin was used as the starting material. Chemical composition of 55.36 wt.- $\% \mathrm{SiO}_{2}, 12.1$ wt.- $\% \mathrm{Al}_{2} \mathrm{O}_{3}$, 8.30 wt.-\% $\mathrm{Fe}_{2} \mathrm{O}_{3}, 7.58$ wt.-\% MgO, 7.23 wt.-\% $\mathrm{CaO}$, and 3.91 wt.- $\% \mathrm{~K}_{2} \mathrm{O}$ was obtained by X-ray fluorescence analysis. Quantitative phase analysis according to Rietveld refinement of XRD data yield 23.4wt.-\% kaolinite and illite beside $74.6 w t .-\%$ of quartz within this material. These phases had low solubility and activity in the hydrothermal reaction process $[15,16]$. Thus, before obtaining the aluminosilicate gel, natural QHS activation must be achieved. While studies of activated method of natural clay had been carried out by several research groupings $[17,18]$, the variety of compositions of natural clay throughout the world mean that it was important to explore the activated method of QHS.

Two activated methods were discussed in this paper, thermally activated and alkaline-fused. According to the XRD analysis, thermally activation by calcination at $800^{\circ} \mathrm{C}$ for $3 \mathrm{~h}$ was not an effective way to activate the natural QHS, although this method have been widely adopted for the activation of natural kaolin. This may be associated with the high content of iron in the QHS [19]. Even if the QHS was treated with $\mathrm{HCl}$ to reduce the content of iron (from 8.303 to $1.04 \mathrm{wt} . \%$ ), some of the quartz still remained after calcination at $800^{\circ} \mathrm{C}$ for $3 \mathrm{~h}$. Instead, QHS would be fully activated through fusion using $\mathrm{NaOH}$ at $500^{\circ} \mathrm{C}$ for $4 \mathrm{~h}$. The results indicate that the optimized experimental parameters to produce pure SBA-15 products were treated the QHS after iron-removing with $\mathrm{HCl}$ at $80^{\circ} \mathrm{C}$ for $2 \mathrm{~h}$ and crystallized at $80^{\circ} \mathrm{C}$ for $24 \mathrm{~h}$.

Table 1 The chemical compositions (wt.\%) of samples as oxides obtained by XRF.

\begin{tabular}{cccc}
\hline Component & Content in QHS & $\begin{array}{c}\text { Content in } \\
\text { iron-removing } 0 H S\end{array}$ & $\begin{array}{c}\text { Content in product } \\
\text { SBA-15 }\end{array}$ \\
\hline $\mathrm{SiO} 2$ & 55.364 & 78.4 & 66.7 \\
$\mathrm{Al2O} 3$ & 12.103 & 12.9 & 0.0210 \\
$\mathrm{Na} 2 \mathrm{O}$ & 0.460 & 1.38 & 0.0125 \\
$\mathrm{~K} 2 \mathrm{O}$ & 3.910 & 3.42 & 0.0021 \\
$\mathrm{Fe} 2 \mathrm{O} 3$ & 8.303 & 1.04 & 0.0033 \\
$\mathrm{CaO}$ & 7.230 & 0.827 & 0.0079 \\
$\mathrm{MgO}$ & 7.580 & 0.759 & 0.0068 \\
$\mathrm{TiO} 2$ & 1.084 & 0.729 & -- \\
\hline
\end{tabular}

\subsection{Characterization of mesoporous silica SBA-15}

Chemical compositions. The chemical compositions of the samples determined by XRF were given in Table 1. The main constituents of raw QHS were silica and alumina which provided the possibility for the synthesis of mesoporous silica. The content of iron in QHS was significantly reduced after iron-removing pretreatment by hydrochloric acid. According to the XRF analysis, the final product SBA-15 contained little Al.

XRD analysis and morphological characterization.

Fig. 1 shows the wide-angle X-ray diffraction (WAXRD) patterns of the samples at various stages of the transformation process. The major composition of raw QHS was quartz; the remainder of the material was made up of kaolinite, illite and albite (Fig. 1a). The XRD pattern of the thermally activated QHS (without iron-removing treatment) had no noticeable changes (Fig. 1b). Even for the iron-removing QHS, calcination could not make it fully activated (Fig. 1c), some of the quartz still 
remained. While fusing by $\mathrm{NaOH}$ at $500^{\circ} \mathrm{C}$ for $4 \mathrm{~h}$, the water-soluble aluminosilicates and sodium silicate were formed (Fig. 1d) indicating the fusion activation was effective. WAXRD pattern of the product revealed that the synthesized product was amorphous; no obvious crystalline impurities were observed in the final top product (Fig. 1e).

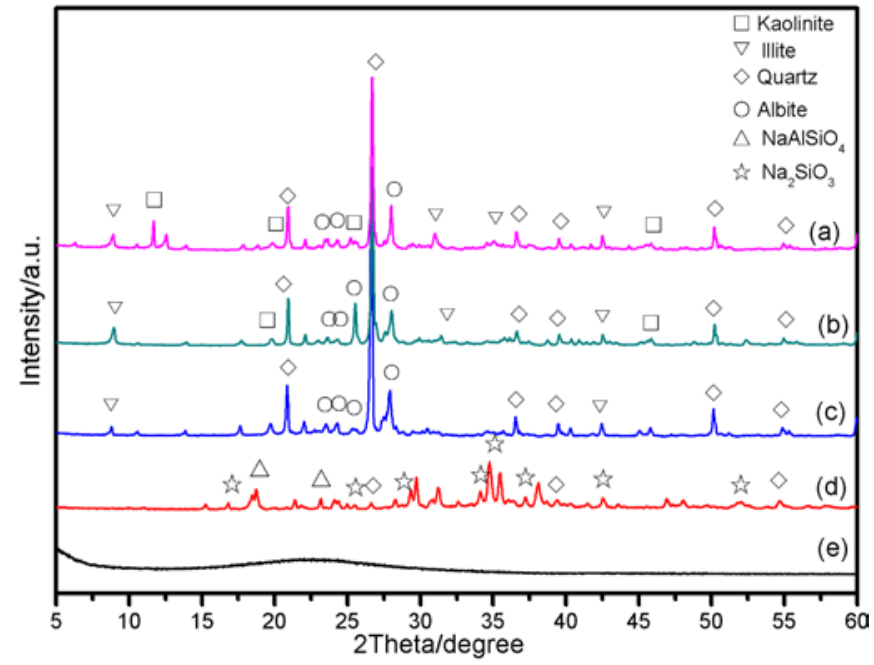

Fig. 1 WAXRD patterns of (a) raw QHS, (b) thermally activated QHS (without iron-removing), (c) thermally activated QHS (after iron-removing),(d) alkaline-fused QHS (after iron-removing) and (e) product SBA-15.

The small-angle X-ray diffraction (SAXRD) pattern of the product was shown in Fig. 2, which exhibited one intense peak accompanied by two weak peaks, indexed to the (100), (110) and (200) diffractions planes in the p6mm symmetry, respectively. The XRD patterns were typically observed for materials characterized by an ordered hexagonal array of a one-dimensional channel structure [20]. According to the equation $a_{0}=2 d_{100} / \sqrt{3}$, the unit cell parameter $a_{0}$ was $10.86 \mathrm{~nm}$, which was similar to that reported in the literature [21]. Ordered hexagonal arrays of mesopores with pore size of ca. $7.9 \mathrm{~nm}$ were further demonstrated by TEM images (Fig. 2, inset).

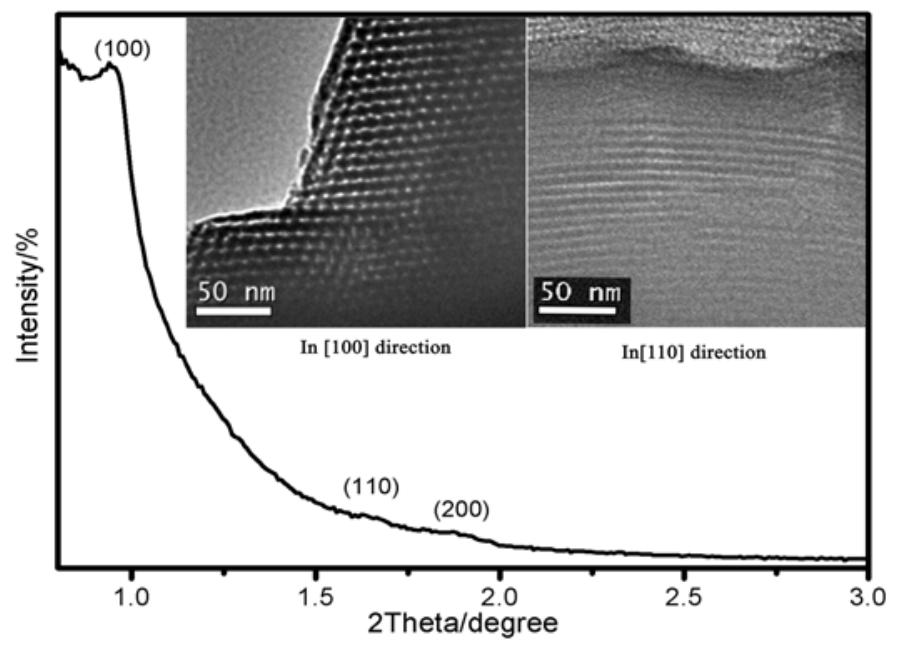

Fig. 2 SAXRD pattern and TEM images of the calcined product.

FTIR spectra. Further information on the transformation of natural clay to a hexagonally mesoporous structure was obtained by FTIR spectroscopy (Fig. 4).

Among them, sample (a) was as-synthesized SBA-15 produced using QHS removed iron as material. Sample (b) was calcined product which was synthesized making use of QHS unremoved iron. Sample(c) was calcined SBA-15 prepared utilizing QHS removed iron as material. In the spectrum of the as-synthesized sample (Fig. 4a), bands at 3418 and $1643 \mathrm{~cm}^{-1}$ were ascribed to Si-OH, bands at 2974, 2934, 1462, 1377 and $1348 \mathrm{~cm}^{-1}$ were attributed to the characteristic bands of the surfactant and almost completely disappear in the calcined sample. In-plane and out-of-plane asymmetric Si-O stretching vibrations at 1083 and $1205 \mathrm{~cm}^{-1}$ in the as-synthesized sample were 
shifted to 1076 and $1219 \mathrm{~cm}^{-1}$, respectively, in the calcined sample. Peaks at $797 \mathrm{~cm}^{-1}$ for the as-synthesized sample and $806 \mathrm{~cm}^{-1}$ for the calcined sample may be attributed to tetrahedral Si-O symmetric stretching vibrations. The band at 454 or $458 \mathrm{~cm}^{-1}$ was assigned to Si-O-Si bending vibrations. The most important peak at $951 \mathrm{~cm}^{-1}$ for the as-synthesized sample and $958 \mathrm{~cm}^{-1}$ for calcined sample were attributed to stretching vibrations of amorphous silica, which demonstrates the sample was mesoporous material. However, peak at $951 \mathrm{~cm}^{-1}$ or $958 \mathrm{~cm}^{-1}$ was not emerged in calcined sample (Fig. 4b), which showed that the sample was not mesoporous materials. The FTIR spectra were very similar to results reported previously [22], which suggests successful formation of the SBA-15 framework.

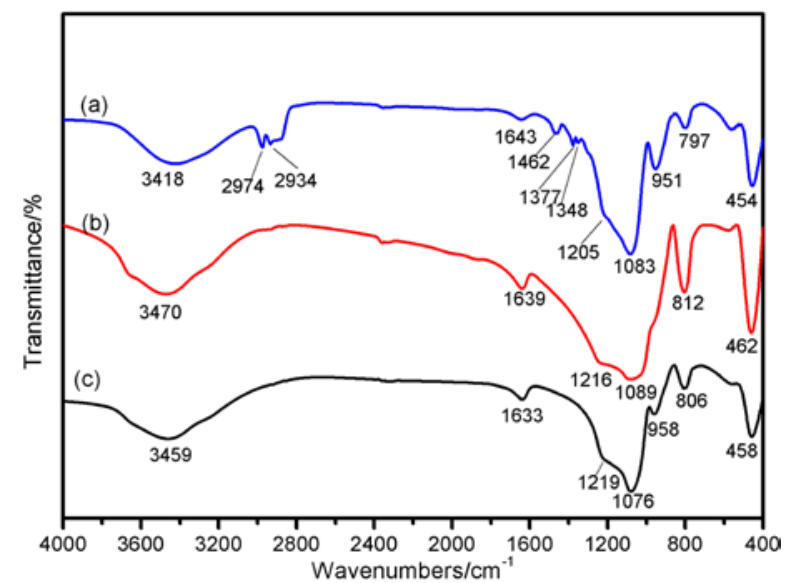

Fig. 3 FTIR spectra of (a) as-synthesized SBA-15(iron-removed QHS), (b) calcined sample (iron-unremoved QHS) and (c) calcined SBA-15 (iron-removed QHS).

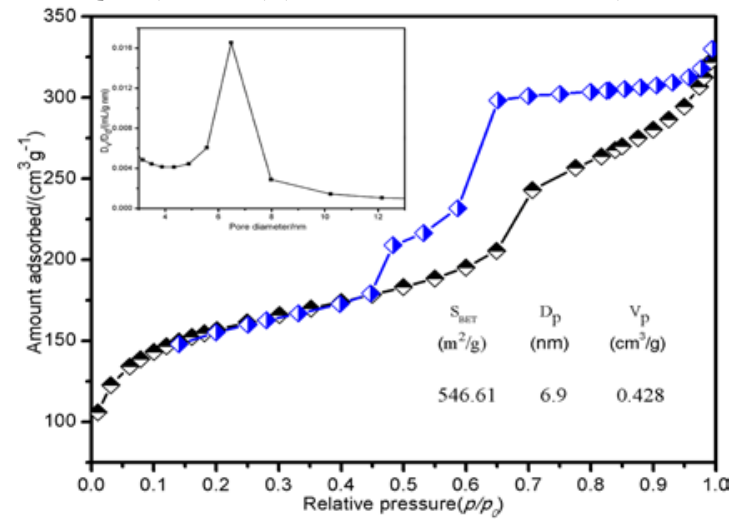

Fig. 4 Nitrogen adsorption-desorption isotherms and BJH pore size distribution (inset) of calcined SBA-15.And surface area (SBET), pore size (Dp), and pore volume (Vp)

Porosity measurements. Representative nitrogen adsorption-desorption isotherms and the pore size distribution of calcined SBA-15 were shown in Fig. 4. On the basis of the IUPAC classification, the isotherm of the calcined sample exhibited a typical type IV class with a H4-type hysteresis loop characteristic of SBA-15 mesoporous materials. A sharp inflection at $P / P_{o}=0.6-0.8$ was clearly observed in the isotherm, and corresponded to capillary condensation within uniform mesopores.

The pore size distribution curve showed a narrow pore size distribution centered at $6.5 \mathrm{~nm}$ and an average pore size of $6.2 \mathrm{~nm}$. The BET surface area of SBA-15 was $546.61 \mathrm{~m}^{2} \cdot \mathrm{g}^{-1}$ and its pore volume, similar to materials synthesized by conventional routes using chemical reactants [21], was 0.43 $\mathrm{mL} \cdot \mathrm{g}^{-1}$.

Thermal analysis. To evaluate the thermal stability of the product, the thermo gravimetric (TG) weight-change curve and the differential scanning calorimetry (DCS) curve for the as-synthesized SBA-15 were presented in Fig. 5.

As observed, the TG profile showed two stages of weight loss. The weight loss below $200^{\circ} \mathrm{C}$ (about $0.94 \%$ ) was apparently attributed to physically adsorbed water. The following significant weight loss of $46.7 \%$ located at temperatures ranging from 200 to $700^{\circ} \mathrm{C}$, which corresponds to the two exothermic peaks centered at about $333.8^{\circ} \mathrm{C}$ and $396.2^{\circ} \mathrm{C}$ in the DSC curves, was mainly related 
to the two steps thermal decomposition of the organic templating agent(P123) [23]. There is a huge exothermic peak centred at about $705.9^{\circ} \mathrm{C}$ could be observed but no obvious weight loss over $700^{\circ} \mathrm{C}$, indicating the loss of surface hydroxyl groups of SBA-15. The TG-DSC analysis shows that the organic templating agent can be removed at $540^{\circ} \mathrm{C}$, without destroying the structure.

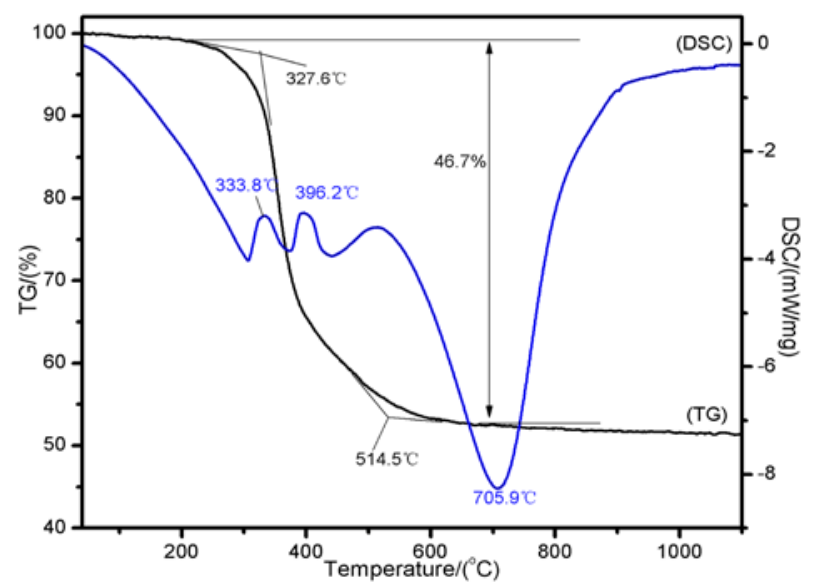

Fig. 5 TG-DSC curves of as-synthesized SBA-15 sample.

\section{Conclusions}

The hexagonally ordered mesoporous molecular sieve SBA-15 with uniform pore sizes has been successfully synthesized via hydrothermal treatment using natural clay as source material, without addition of silica reagents. The alkali fusion has been demonstrated to be effective method for the activation of natural QHS clay. The product was extensively characterized, and results indicated that QHS is an appropriate precursor for synthesizing mesoporous molecular sieve. The product exhibits highly thermal stability and specific surface area of $546.61 \mathrm{~m}^{2} \cdot \mathrm{g}^{-1}$, pore volume of $0.428 \mathrm{~mL} \cdot \mathrm{g}^{-1}$, and pore size distribution centred at $6.5 \mathrm{~nm}$.

\section{Acknowledgements}

The authors thank the support of National Natural Science Foundation of China (No. 21266027) and Ministry of Education of China, "Chunhui Plan" (No. Z2012087).

\section{References}

[1] A. H. Lu, W. Schmidt, N. Matoussevitch, et al. Nanoengineering of a Magnetically Separable Hydrogenation Catalyst. Angew. Chem. Int. Ed.. Vol. 43(2004) No. 33, p.4303-4306.

[2] S. L. Zhang, L. Chen, S. X. Zhou, et al. Synthesis of Hierarchically Ordered Porous Carbon via in Situ Self-Assembly of Colloidal Polymer and Silica Spheres and Its Use as a Catalyst Support. Chem. Mater.. Vol. 22(2010) No.11, p.3433-3440.

[3] O. Berg, M.S. Hamdy, T. Maschmeyer, et al. On the Wavelength-Dependent Performance of Cr-Doped Silica in Selective Photo-Oxidation. J. Phys. Chem. C. Vol. 112(2008) No. 14, p.5471-5475.

[4] Y. P. Zhai, Y. Q. Dou, X. X. Liu, et al. One-pot synthesis of magnetically separable ordered mesoporous carbon. J. Mater. Chem.. Vol. 19(2009)No.20, p.3292-3300.

[5] D. Saha, S. G. Deng. Hydrogen Adsorption on Ordered Mesoporous Carbons Doped with Pd, Pt, Ni, and Ru. Langmuir. Vol. 25(2009) No. 21, p.12550-12560.

[6] Y. Y. Yin, S. X. Zhou, C. Min, et al. Preparation of rattle-type magnetic mesoporous carbon spheres and their highly efficient adsorption and separation. J. Colloid Interface Sci.. Vol. 361(2011) No. 2, p. 527-533. 
[7] A. H. Yan, B. W. Lau, B. S. Weissman, et al. Biocompatible, Hydrophilic, Supramolecular Carbon Nanoparticles for Cell Delivery. Adv. Mater.. Vol. 18(2006) No. 18, p. 2373-2378.

[8] Y. Fang, D. Gu, Y. Zou, et al. A Low-Concentration Hydrothermal Synthesis of Biocompatible Ordered Mesoporous Carbon Nanospheres with Tunable and Uniform Size. Angew. Chem. Int. Ed.. Vol. 49(2010) No. 43, p.7987-7991.

[9] T. P. B. Nguyen, J. W. Lee, W. G. Shim, et al. Synthesis of functionalized SBA-15 with ordered large pore size and its adsorption properties of BSA. Micropor. Mesopor. Mat.. Vol. 110(2008) No. 2-3, p. 560-569.

[10] X. L. Gue'veln, R. Nooney, C. McDonagh, et al. Synthesis and characterization of monodisperse, mesoporous, and magnetic sub-micron particles doped with a near-infrared fluorescent dye. J. Solid State Chem.. Vol. 184(2011) No. 6, p. 1545-1550.

[11] H. Yang, A. Tang, J. Ouyang, et al. From natural attapulgite to mesoporous materials: methodology, characterization and structural evolution. J. Phys. Chem. B. Vol.114(2010) No. 7, p.2390-2398.

[12] Y. Xie, Y. Zhang, J. Ouyang, et al. Mesoporous material Al-MCM-41 from natural halloysite. Phys. Chem. Miner.. Vol. 41(2014) No. 7, p. 497-503.

[13] T. Linssen, P. Cool, M. Baroudi, et al. Leached natural saponite as the silicate source in the synthesis of aluminosilicate hexagonal mesoporous materials. J. Phys. Chem. B. Vol. 106(2002) NO. 17, p. 4470-4476.

[14] M. Adjdir, T. Ali-Dahmane, F. Friedrich, et al. The synthesis of Al-MCM-41 from volclay-a low-cost Al and Si source. Appl. Clay Sci. Vol. 46(2009) No. 2, p. 185-189.

[15] C. Wang, J. Zhou, Y. Wang, et al. Synthesis of zeolite X from low-grade bauxite. J. Chem. Technol. Biotechnol..Vol. 88(2013) No. 7, p.1350-1357.

[16] A. S. Kovo, O. Hernandez, S. M. Holmes. Synthesis and characterization of zeolite Y and ZSM-5 from Nigerian Ahoko Kaolin using a novel, lower temperature, metakaolinization technique. J. Mater. Chem..Vol. 19(2009), p.6207-6212.

[17] M. Mezni, A. Hamzaoui, N. Hamdi, et al. Synthesis of zeolites from the low-grade Tunisian natural illite by two different methods. Appl. Clay Sci..Vol. 52(2011) No. 3, p.209-218.

[18] Y. N. Ma, C. J. Yan, A. Alshameri, et al. Synthesis and characterization of 13X zeolite from low-grade natural kaolin. Advanced Powder Technology, 25(2014)No. 2, p.495-499.

[19] M. Murat, A. Amokrane, J. P. Bastide, et al. Synthesis of zeolites from thermally activated kaolinite; some observations on nucleation and growth. Clay Minerals. Vol. 27(1992), p.119-130.

[20] D. Y. Zhao, Q. S. Huo, J. L. Feng, et al. Nonionic Triblock and Star Diblock Copolymer and Oligomeric Surfactant Syntheses of Highly Ordered, Hydrothermally Stable, Mesoporous Silica Structures. J. Am. Chem. Soc..Vol. 120(1998) No. 24, p. 6024-6036.

[21] T. da Silveira, C. M. Awano, D. A. Donatti, et al. About the thermal stability and pore elimination in the ordered hexagonal mesoporous silica SBA-15. Microporous Mesoporous Mater..Vol. 190(2014), p. 227-233.

[22] X. Y. Sun, F. B. Ma, X. K. Shi, et al. Adsorption of Pd( II ) on SBA-15 synthesized from fly ash. Journal of Central South University (Science and Technology).Vol. 45(2014)No.11, p. 4093-4099.

[23] W. L. Xie, X. L. Yang, M. L. Fan. Novel solid base catalyst for biodiesel production: Mesoporous SBA-15 silica immobilized with 1, 3-dicyclohexyl-2-octylguanidine. Renewable Energy. Vol. 80(2015), p.230-237. 